\title{
On Smart City and Safe City Concepts
}

\author{
Jozef Ristvej $^{1}$ (iD $\cdot$ Maroš Lacinák ${ }^{1}$. Roman Ondrejka ${ }^{2}$
}

Published online: 13 February 2020

(C) The Author(s) 2020

\begin{abstract}
With current environmental and social challenges in mind, we can say, that Smart Cities are becoming the need of modern society. Many cities in the world are already transforming their ways to be more efficient, greener and also safer. According to our studies, field of safety receives less focus in development strategies than other fields of smart development. However, to create a real Smart City, it is needed to understand the city as a complex environment, with their smart and safe concepts as interconnected parts. This paper deals with interconnected Smart City and Safe City concepts and it presents systems, that are common to both, equal concepts. Systems are divided into layers and features, needed in every system, are further summarized. Number of studied and compared works, dealing with respective systems from various points of view, our own experiences and communication with executives, responsible for smart development of Tampere city resulted in definitions, describing both concepts and each of the system layers, that are presented. The big picture was visualised by a structure for concepts and their systems, where the reader can see their relationships. Overview, of how smartness can improve safety is presented within description of specific system Smart Safety and Smart Healthcare.
\end{abstract}

Keywords Smart City $\cdot$ Safe City $\cdot$ Common systems $\cdot$ Layers $\cdot$ Features

\section{Introduction}

To become a Smart City is a vital goal of all modern cities. Today, in the world there are already many cities, successfully reaching smartness in some fields. In the Slovak Republic, some cities, such as the capital city of Bratislava, Košice, Poprad and later also Žilina and others are advancing in reaching this goal as well, but a common understanding of what does it mean to be a Smart City, what are its systems and features is still not defined. Also, there is often lack of importance given to the concept of Safe City, even though safety is with no doubt important quality of a city.

After this introduction, second chapter of this article will describe the structure and relationships of Smart City and Safe City concepts as we understand them with brief explanation of every structural level and of dividing the systems into layers.

Jozef Ristvej

Jozef.Ristvej@uniza.sk

1 Faculty of Security Engineering, University of Žilina, Univerzitná 1, 01026 Žilina, Slovakia

2 Transport Research Institute,Inc., R\&D Division, Vel'ký Diel 3323, 01008 Žilina, Slovakia
Those two concepts are interconnected and systems, presented below, belong to both systems.

The third chapter will then continue with defining concepts Smart City and also Safe City. Fourth chapter will summarize all the systems of the Smart City concept, describes their smart and safe layers and further summarizes features, needed in every system.

\section{Structure of concepts and systems}

For better understanding of the concepts, a structure of relations within the concepts was set up, breaking them into smaller groups. Those groups are: systems, layers and features. Components are the individual solutions, the smallest parts of the hierarchy. The relationships between components, systems and layers are illustrated in the Fig. 1. In this chapter, the structure and relations are explained. The actual definitions will be presented in following chapters.

\subsection{Concepts}

Concept, as this term is used in our work, is a complex vision about the future condition from the point of view of specific philosophy - in our cases philosophy of smartness of the city, 
Fig. 1 Structure and relations between concepts Smart City and Safe City, their common systems and separate layers (own creation, previously published in: Concept Safe City and system of Smart Safety and Smart Healthcare modified)

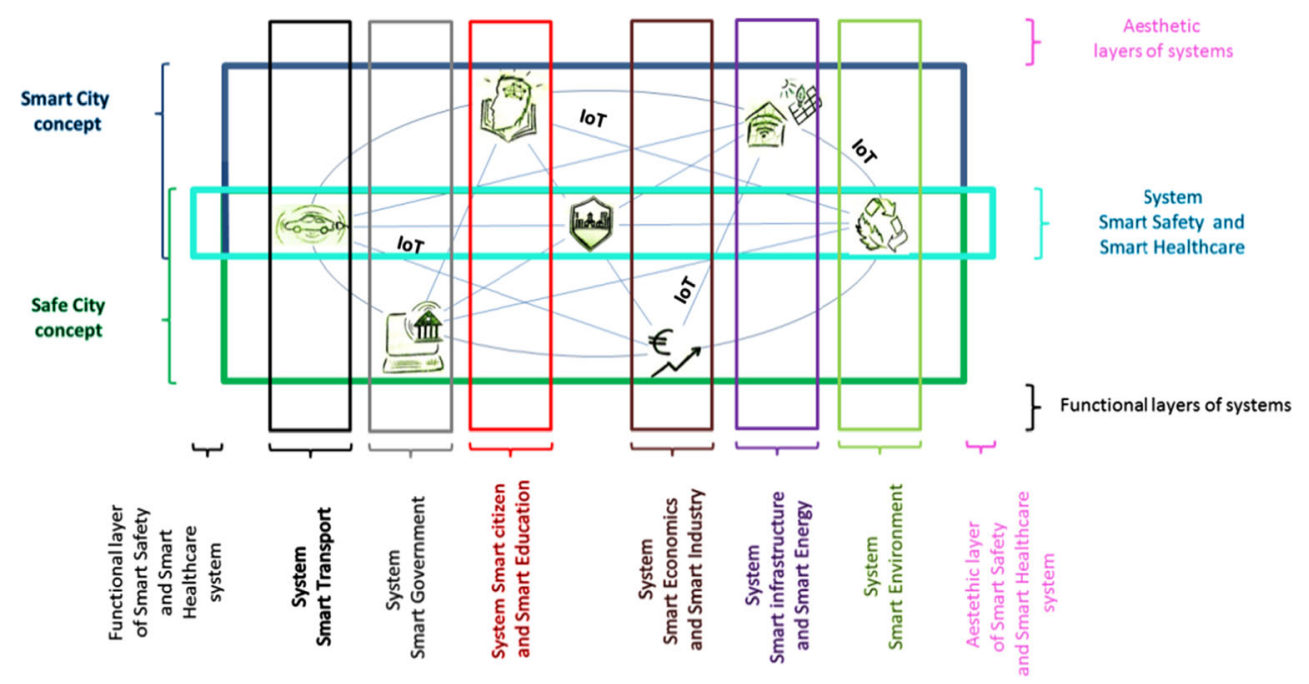

or its safety. Development and implementation of the concept is enacted in individual systems of the concept. Concepts of Smart City and Safe City are equal; partially blend together and they consist of the same systems. While identifying of the systems, we were influenced by the strategies of the Finnish cities of Tampere and Helsinki [1-3] and personal communication with Mr. Ville Haapakangas.

\subsection{Systems and layers}

First, there is a group of systems. Every system belongs to both concepts, is divided into four layers and consists of many features, that belong to one or sometimes more layers. Layers are illustrated in the Fig. 2, and smart and safe layers of every system are defined in the chapter 3.

The first layer is a functional one. It consists of components, that serve for the functionality of given system, without further addressing the safety or smartness of solutions.

The second layer is safety layer. It includes components and parts of components, that primary serve for complex protection of users, components of the systems and their surroundings.

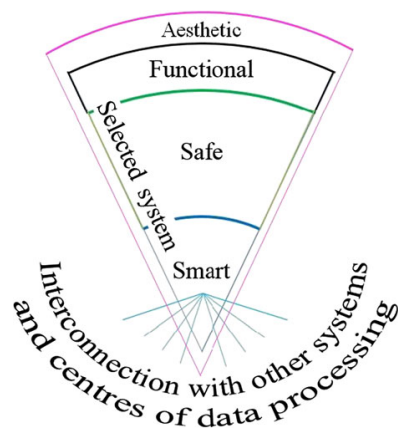

Fig. 2 Visualisation of layers of selected smart system (own creation, previously published in: Concept Safe City and system of smart safety and smart healthcare - modified)
The third layer includes intelligent components. The research of the Smart Cities deals mainly with these layers of systems. As was mentioned before, concepts of Smart City and Safe city are partially blend together, and the same can be said about some components, that serve for the safety and smartness of the system at the same time.

The fourth layer covers the aesthetics of the system components. Design sometimes also belongs to functional, safe or smart layer, but often pursues only the aesthetic function without another meaning.

In this layout it can be seen, that systems in certain ways exceed borders of concepts. The intersection of given system with the Smart City Concept creates the smart layer; the intersection of the system with the Safe City Concept creates the safe layer. Specific example is the system of Smart Safety and Smart Healthcare. This system itself is an intersection between Smart and Safe City concepts and it is also cross-sectional system, that covers safe layers of every other system.

Positive practise is to build such components within systems, that will serve more than one layer. Modern production should aim at creating technology that will be functional in use, safe for people, environment and itself, smart in its possibilities and aesthetically appealing.

As an example of how the component changes, when it wants to serve additional layer, we can use primarily functional tool, as simple as a screwdriver. The screwdriver, that serves only to the functional layer, is a piece of metal with desired bit. If it should serve also to the safe layer, than the handle of the screwdriver is made comfortable, likely covered by rubber, so that the hand of the user will not get cut after a while of use and materials, that cause some harm to the user if touched will be definitely excluded from consideration. Getting higher into safety standards, electronic screwdriver takes place, protecting professional workers from overexertion of their wrists. By this addition, smart layer is overlapped as well, because electrification serves not only to safety, but it also speeds up the 
process. It can also automatically change bit, according to the need, or communicate with central station, giving information about its location, work load, battery information and so on. And finally, electronic screwdriver can also look good, with shiny colour, that will make it easy for workers to find it in various environments.

\subsection{Features and components}

The features are subgroup of the systems. While the systems represent different fields of research within the philosophy of systems, features have direct relation with the focus of its system.

Components are individual, particular solutions for given concept, system and feature. For example, for the concept of Safe City, system of Smart Transport and feature "tools for prediction of impacts of various crisis phenomena on traffic and planning of evacuation and backup routes", simulation program VR Forces $₫$ can be presented. It is used in the Laboratory of Modelling and Simulation of Crisis Phenomena in Transport in the University Science Park of the University of Žilina. This component belongs to the safe layer of the system.

Fast development of technologies causes, that features and components are not finally enclosed issue. In every layer, new features, that we did not yet made provision for, can emerge. Of course, features can be further divided into smaller groups, but those are not the essential subject of the research and so, the paper does not deal with deeper dividing.

\section{Defining of concepts}

Our research works with two concepts: Smart City and Safe City.

The Smart City itself was defined in our work as the city, that by the interconnection with the Safe City concept, and integration of technology and natural environment enhances the effectivity of processes in every field of the city functioning to achieve sustainable development, safety and health of citizens in order to increase the life standard of citizens of the city and its region.

In some of our previous articles [4] the term Safe City was used as one of the systems within Smart City concept. Later during our work, we came to an opinion, that this perception does not cover the whole scope of the urban safety. That is why we think, that an extension to the given system is needed.

As such an extension, this paper presents the Safe City as a concept, equal to the concept of the Smart City. The two concepts are partially blended together. Their intersection is a system, originally introduced as the Safe City system. Later on, we changed its name into the Smart Safety and Smart Healthcare system, to make it more coherent with other systems. Its cross-sectional character illustrates, that all the systems of the Smart City and Safe City concepts have to be safe. This basically means, that every applied component must be safe to the user, wider environment and itself. Systems of Smart City therefore have their roots in the concept of Safe City, they belong to both concepts. While the Smart City deals with possibilities of components usage within systems, Safe City ensures protection of society, property, environment and these components, their informational, cybernetic and physical safety. In a way, Safe City is a term, that deals not only with the intelligent innovations, but uses also older useful solutions, not yet depending on the intelligent technologies.

The term safe city itself is used in the professional literature, even though it has not been so frequently and deeply addressed as Smart Cities. While most resources focus on reducing crime by using security cameras [5, 6] Fedorov et al. (2012) has broader insight. In their work, as the goals of a Safe City are considered also creation of a unified plan of response to major crises and improvement of safety and quality of life by reduction of crime, urban violence and terrorist threats, and by acceleration of responsiveness to crisis phenomena [7].

According to Finka et al. (2016), smart concept of the urban safety includes a wide range of aspects and activities linked to public spaces, from crime prevention to physical protection of the environment, accessibility, to institutional and organizational aspects [8].

We consider the Safe City concept as one of the basic, necessary condition for the creation of a Smart City, and in this paper the two are defined in a similar way.

Concept Safe City by the by the interconnection with the Safe City concept and by the use of physical, organizational, hardware and software means of protection increases the effectiveness of processes in the field of urban safety and health by minimization of crime and terrorist threats, in order to allow citizens life in a healthy and sustainable environment and a simple access to quality healthcare and in order to reach high levels of preparedness, resilience and fast reaction ability to threatening or arose crisis phenomena.

\section{Defining of system layers}

When it comes to defining the individual systems of these concepts, this paper rather takes closer look on respective layers. Smart layers and safe layers of every system were defined. In general, it can be said, that if we want to define the system itself, the definition would always go down to satisfying all the definitions of each respective layer.

Defining the system layers was approached with three basic aspects in mind:

- Tools (what does the system use within this layer?). 
- Outputs (what does the system create or what it does by the use of previously identified tools?).

- Aims (how do outputs change the city and the life of citizens? Why should we want it?).

The final definitions try to cover all of those aspects and questions. To maintain compact form of definitions, many details had to be contained in a generalized description. Except for the system of Smart Safety and Smart Healthcare, that is a cross-sectional system, every other system has defined its smart layer and safe layer separately.

Prior to every definition, many scientific and practical sources were studied to cover a wide range of previously defined approaches. Those are usually mentioned before the definition itself in a separate clause. Afterwards, the results were consulted with the members of Smart Tampere Team, as Tampere is considered as one of the smartest medium-sized city in Europe [9].

\subsection{Smart transport system}

Smart Transport system is one of the most discussed systems. It affects all citizens and administrative and business bodies within the city as well by its many impacts, such as pollution, street congestion, travel times across the city and so on. Its importance can also be seen from the fact, that inadequate transport systems constrain a city's economy and vitality and can cause a loss of valuable space. Therefore dealing with transport needs to be tied with the housing and land use policy. It also needs to take into account the density of the city. The most dense points are becoming the centres, where it is the most convenient to gather shops and services, so that no one has to walk - or drive a great distances to get, what is needed. From this point of view, one may say, that smart and sustainable city should be dense [10].

The most important sources that helped to define its smart and safe layer were references 10 to 15 [10-15].

Smart transport layer is the part of the Smart Transport system, that by the integration of smart technology, planning and construction increases the effectiveness of transport and movement of citizens and goods in the city and surrounding region, in order to reduce transport times, noise, costs, unnecessary economic charges and traffics congestion to minimize air pollution and to allow simple access to any public area through the city, even to the people with special needs.

As well as the other systems of Safe City, Smart Transport system too partially belongs to the concept of Safe City with its safe layer.

Safe layer of the Smart Transport system by the use of technology, planning, construction, traffic rules and supervision minimalizes the amount of various traffic accidents in order to increase the safety of all traffic users and means of transportation and safety and integrity of traffic infrastructure.
The layers of the Smart Transport system should include following features:

- Functional layer: quality roads and other transport lines, bridges and tunnels, means of transportation, road signs, relevant data.

- Safe layer: safe parking systems, data monitoring sources from critical parts of infrastructure (supervision management), tools for prediction of impacts of various crisis phenomena on traffic and planning of evacuation and backup routes, traffic rules.

- Smart layer: UMT (urban mass transportation) systems: UMT preference traffic, with effective back-to-back connections and possibility to adjust services in order to meet changing commuter needs, preference and support of emission-free vehicles, bicycles and pedestrians, smart parking systems, effective road signs and traffic lights system with real time adjustments, real time informational tools for traffic consumers, intelligent tools for collection and work with data, planning and prediction of results of changes in the traffic, drone management, solutions for shortening everyday travel needs.

\section{- Design and other features.}

Because of already wide and still rapidly growing pool of possibilities, identified features are not definite, and they can be further divided into more specific fields, but it is not the concern of this article to go too deeply in every system.

\subsection{Smart government system}

Studied articles, that helped to define layers of the Smart Government system were references 16 to 21 [16-21].

Smart layer of the Smart Government system by the integration of smart information systems and communication networks creates transparent governance and effective digital government and with innovative policies fights financial, environmental and service challenges of the city in order to achieve long-term benefits and smart development of the city.

Safe government layer by the use of software, construction, organizational solutions and tools increases the cybernetic safety of used systems and connections, the safety of government executives, objects and facilities, as well as the safety of people and their possessions in an administered region in order to ensure the resilience of government functioning and to raise the law abidance and the trust of citizens towards the government.

Digital government should digitalize city services and help with communication within government and its departments and also between government and citizens, helping both sides to better understand the reasoning and requirements of the other and enabling participation of the citizens in the city planning. Transparent governance and quality and 
accessibility of services and information are important factors of smart government.

Services should be improved by minimalization of bureaucratic delays and increasing the efficiency of bidirectional interactions, while taking into account also the needs and experiences of tourists.

Features of Smart Government system include:

- Functional layer: the law, hierarchical and functional system of executives, government objects, facilities and offices, relevant data.

- Safe layer: secure internet connection and communication systems (including Intranet), law enforcement, justice system.

- Smart layer: smart development policies, user friendly and effective digital government, effective communication systems, open data for the public.

- Design and other features.

\subsection{Smart citizen and smart education system}

In order to create a Smart City, we must realize that even the most advanced technology is not answering its purpose, if the citizens are unable to understand the vision of a Smart City and to embrace its possibilities. Current education needs to be adjusted, so that it will let students grow into smart citizens, aware of their possibilities, rights and duties. With defining this wide system, the most important sources were references 22 to 27 [22-27]. The definition of this system is a bit different form the others, because rather than using technologies and tools to create something new, it focuses more about the attitude, behaviour, knowledge, information sharing and the ability of citizens to use available information.

Smart layer of the Smart Citizen and Smart Education system presents a cooperation and relationships between government, Smart City stakeholders, teachers and citizens and students, where in the welcoming atmosphere teachers are to guide the students through all-round theoretical and practical knowledge, knowledge about all the smart systems and deeper about students' individual strengths and interests for a future job and daily decent, cultural and healthy life, raising a smart citizen, who are knowledgeable about the reason and the use of smart technologies to their full potential, interested in participation on the city planning, taking smarter decisions, based on real-time data and who by the use of smart devices participate on sustainability of development and gives feedback for further improvement.

For the most part, the safety of Smart Citizen and Smart Education system is handled by the Safe City concept. Safe layer of the Smart Citizen and Smart Education system contributes to overall safety by raising citizens with a strong moral base, educated in first aid actions, in behaviour during crisis situations and survival basics and in some cases also by raising experts with higher education in safety-oriented fields of study.

Features of Smart Citizen and Smart Education system are:

- Functional layer: students, teachers, citizen, schools, knowledge and relevant data, culture.

- Smart layer: teaching and learning methodologies, contents of education, smart teaching and learning applications and serious games, citizens' smart habits, smart applications, technologies and devices for everyday citizen use, government, eGovernment, Smart City stakeholders, companies cooperating with students.

- Safe layer: education topics (morality, first aid, crisis behaviour, survival basics, physical education), safety oriented higher education, possibility to learn self-defence, helpline and psychologist services.

- Design and other features.

\subsection{Smart economy and smart industry system}

Industrial companies are an important part of the development and they are needed to participate in technological progress. Most important sources for defining the Smart Economy and Smart Industry system were references 28 to 30 [28-30].

Smart layer of Smart Economy and Smart Industry system by the use of circular, sharing and low carbon economies, smart infrastructures and energy, smart production technologies, industrial digitalization, artificial intelligence, virtual and augmented reality and collaboration between the academic world and companies creates an economy with effective, sustainable ways of production and flexible labour market, that offers diverse economic opportunities to create innovative products for handling maintenance and operational issues, in order to save costs and resources, supporting tourism and striving for sustainable economic growth of the city, its citizens and region.

Safe layer of Smart Economy and Smart Industry system by the use of the circular economy, laws, terms of treaties, smart production technologies, safety tools like switches, aids and devices, safety protocols, automatization, safe internet connection and audits creates an environment, where people can develop their business, invest, buy and sell goods without the fear of being scammed or unjustly deprived of his property, and environment, where the risks of health issues for workers are minimalized in order to support and stimulate the economic growth of the city, its citizens and region in the secure way.

Features of the Smart Economy and Smart Industry system are: 
- Functional layer: companies, shops, banks, start-ups, law and commercial code, employers, employees, customers, goods, relevant data.

- Smart layer: trade policies, sustainable production policies, smart systems for communication, accounting, energy..., business opportunities, networking opportunities, tourist opportunities, requalification opportunities,

- Safe layer: secure internet and intranet connections, secure communicational systems, safety protocols, safety devices, switches, tools and aids.

- Design and other features.

\subsection{Smart infrastructure and smart energy system}

The infrastructure, and the power to operate it. Those are the subjects of this system. It has specific place among the systems of Smart and Safe City concepts, because technologies and tools, previously often working on a mechanic principle, are turning online and into electricity-powered ones. The importance of energy resilience and the infrastructure to deliver it is rising. The most important for defining layers of this system were references 31 to 35 [31-35].

Smart layer of the Smart Infrastructure and Energy system cooperates with Smart Environment system and by the use of renewable energy and smart energy systems enhances grey infrastructure of the city, turns buildings into responsive, energy, digital, sustainable and comfortable, provides reliable telecommunication infrastructure, smart grid and effective and sustainable energetic services, enables centralized control of energy and heating systems, in order to achieve energetically neutral or positive infrastructures, capable of restoring waste energy, carbon neutrality, to make the infrastructure collaborative as a whole and to conform to the needs of users.

For the most part, the safety of infrastructure of the city is again handled by the Safe City concept. Safe layer of Smart Infrastructure and Smart Energy system contributes to infrastructure safety by complying to building codes, equipping the infrastructure with sensors, able to alert responsible personnel about threats and by creating backup energy systems in order to improve the resilience of infrastructure and energy systems and strengthening their ability to work continuously in harsh conditions.

Features of the Smart Infrastructure and Smart Energy system:

- Functional layer: grey infrastructure (buildings, energetics, heating and cooling systems, telecommunication infrastructure), relevant data.

- Smart layer: smart energy systems, smart grid, power plants of renewable energy, energy saving and controlling applications, smart housing systems, waste energy restoring systems.
- Safe layer: building codes, sensors, monitoring the state of the infrastructure component, protective measures for critical parts of infrastructure and energy systems, backup energy systems.

- Design and other features.

\subsection{Smart environment system}

When it comes to an environment in the Smart City concept, people mostly tend to see it as green fields and parks within the cities. Those are surely important, but not the only part of the system. The future on smart technologies is about to fill the environments, green and grey alike, with technologies, that will help us to effectively interact with the environment. On defining the system and its layers, we worked mainly with references 36 to 40 [36-40].

Smart layer of Smart Environment system by the use of smart devices such as sensors and communicational technologies and green infrastructure creates an enjoyable, interactive, automatic, data generating and evaluating environment with enough leisure public spaces in order to make the environment itself support decision-making, to allow effective control and use of the environment, suitable landscaping and development in the line with the philosophy of a sustainable development, where people have enough space for their leisure activities, relaxation, sports and hobbies.

Safe layer of Smart Environment system by the use of smart devices such as sensors and communicational technologies creates automatic data generating environment in order to allow the support of decision-making in response to a crisis phenomena and by the use of natural features of green infrastructure supports nature sanitation, in order to protect ecological system (nature, biodiversity and resources) and thus creating sustainable, clean, healthy and enjoyable ecosystems, that enhance physical and psychical health of citizens.

Possible sources of further information about safety within our environment are works of Nosek and Holubčík et al. [41-43].

In a wider, regional point of view, safe layer cares also about the wellbeing of animals and about the use of land, preserving the natural diversity and ensuring food safety of rural agricultural output.

Features of the Smart Environment system:

- Functional layer: green infrastructure, blue infrastructure (water and wastewater management), grey infrastructure (shared with smart infrastructure system), community (shared with smart citizen system), animals, relevant data, land and agricultural output management.

- Smart layer: smart devices, smart connections, centres for controlling the parts of environment (flats, buildings, city regions...), leisure playfields, landscaping. 
Fig. 3 Features within Safe City concept (own creation, previously published in: Informational needs from perspective of crisis management towards the concept of Smart Cities in Slovakia modified)

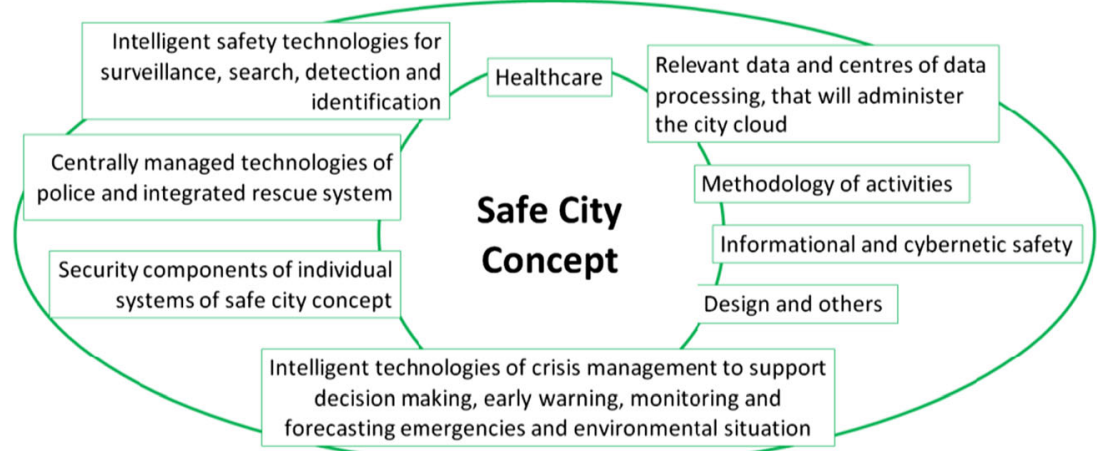

- Safe layer: nature sanitation features, rain water management, heat and emission regulation, decision-making support systems, health monitoring, parks, food safety management.

- Design and other features.

\subsection{Smart safety and smart healthcare system}

As the last one, we present unique, cross-sectional system Smart Safety and Smart Healthcare. This system embraces all the other systems of Smart City and Safe City concepts, because every system has to be safe. It is also the conjunction between Smart City and Safe City concepts. It means that both respective definitions are partially applicable for this system.

System Smart Safety and Smart Healthcare by the use of smart technology, natural environment, physical, organizational, hardware and software means of protection increases the effectiveness of processes in the field of urban safety and health by minimization of crime and terrorist threats, in order to allow citizens life in a healthy and sustainable environment and a simple access to quality healthcare and in order to reach high levels of preparedness, resilience and fast reaction ability to threatening
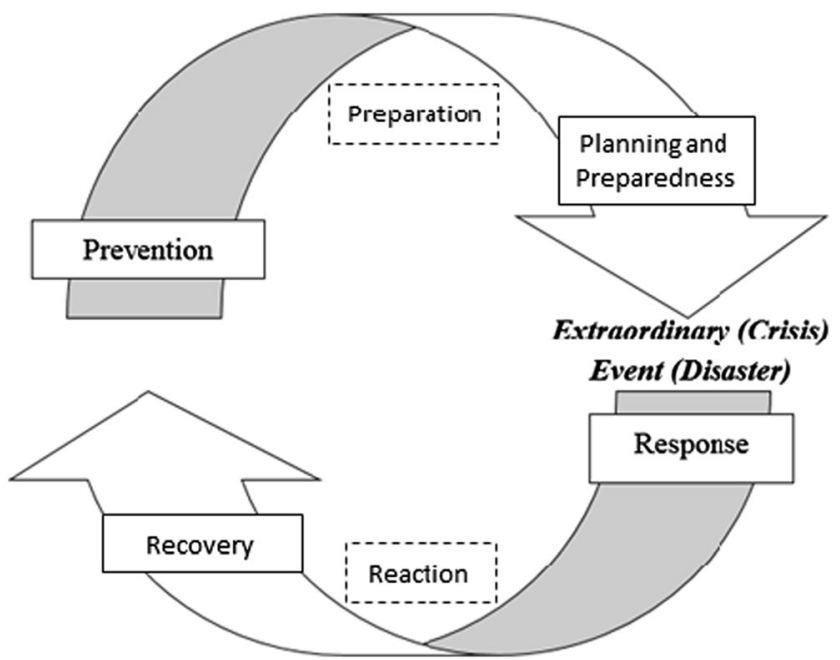

Fig. 4 Disaster management cycle (modified according to [44]) or arose crisis phenomena and to increase the safety of usage and consequences of every system of Smart and Safe City concepts.

Features of the system are not divided into smart and safe layers, because of the specific, cross-sectional character, that means, that whole system belongs to the smart and also safe layer at the same time. Therefore, there are only three layers in this system: the functional layer, the core layer (smart and safe character) and the aesthetic layer. Identified features are visualised in Fig. 3.

It was already mentioned, that systems of Smart City have their roots in the concept of Safe City, because every smart component must be safe. Thus, the need for "Safe" within "Smart" was set up. Here, we shall take a look the other way around and sum up the acquisitions of Smart City concept towards the concept of a Safe City.

Possibilities of enhancing the safety differ through various phases of disaster management cycle. This cycle contains four phases within two periods: pre-crisis and after-crisis. Pre-crisis period is a period of Preparation, second one is a Reaction period. These phases and periods are shown in Fig. 4.

For in-depth identification, it is needed to dive into every phase and look for future possibilities of every Smart City system. Main areas of improvements should be optimisation of needed staff, time, equipment, resources, informational sources and informational flow. In every phase we need to identify possible improvements by asking ourselves:

- What improvements can a smart component of this system deliver in order to optimize amount of staff and time, needed to deal with safety related tasks in this phase of disaster management cycle?

- What improvements can a smart component of this system deliver in order to optimize number of equipment, needed to deal with safety related tasks and what smart equipment can be used in this phase of disaster management cycle to enhance safety?

- What improvements can a smart component of this system deliver in order to optimize expenses for equipment and labour, needed to deal with safety related tasks, how it can minimalize financial and material loses and what 
Table 1 Possibilities of smart components to enhance safety in disaster management cycle

System smart transport

Staff and - Increase in transport effectivity

time $\quad$ Digitalisation and automatization of receiving and evaluation of traffic information

- Supervision of the traffic by technology

- Better estimation of staff and time needed for safety related tasks

Equipment - Speeding up the informedness of drivers about changes in traffic the outcome will be positive or negative)

- Lowering pollution

- Road enforcement systems

- Better estimation of needed equipment

- Integration of emergency and security technologies into cars and specialized tools for IRS and army units into their specialized vehicles

Expenses $\quad$ Real-time gathering of transport data

and $\quad$ Usage of innovative - cheaper materials

sources

System smart government

Staff and $\quad$ Increasing trust of citizens

time $\quad$ Ensure confidentiality of communication between staff

- Improving the ability to react swiftly and effectively

Equipment $\quad$ Enactment of smart policies into the law

- Assessing the safety of individual cities

- Support of implementation of the safe city concept components

Expenses $\quad$ Enactment of smart policies into the law and sources

System smart citizen and smart education

Staff and - Improvement of the ability of citizens to react swiftly and effectively to crisis time phenomena

- Decrease of crime rates

- Preparation of future specialists in the field of safety and security

- Increase of the number of citizens, able to effectively provide first help

Equipment - Increase of cybernetic security awareness

- Decrease of immoderateness

- Promotion of sustainable policies

- Increase of self-defence and self-protection awareness

Expenses $\quad$ Lowering immoderateness

and $\quad$ Promotion of sustainable policies

sources - Increase of financial literacy

- Promotion of sustainable policies

- Decrease of crime rates

System smart economics and smart industry

Staff and $\quad$ Automatization

time - Strengthening personal and organisational preparedness

Equipment - Development, production and implementation of safety equipment, technology,

- Strengthening technological preparedness

Expenses - Sustainable policy, recycling, zero-waste policy,

and $\quad$ Creation of smart accounting support systems

sources

System smart infrastructure and smart energy

Staff and $\quad$ Reducing speech-path switching times time

Equipment - Increase of the sustainability of energy sources

- Increase of the resilience of infrastructure, informational and energetic networks

- Tools for help in crisis situations embedded in infrastructure

Expenses - Analysation of most cost-effective build of networks in specific circumstances and

Sources

System smart environment

Staff and $\quad$ Provision of visual stimulation at workplaces

time $\quad$ Provision of relaxation and possible leisure activities by green and blue infrastructure

- Automatic, constant monitoring of the environment

Equipment - Provision of real-time data from the environment

- Purification of the environment

- Simulation of crisis phenomena to more precise estimation of endangered areas

Expenses - Simulation of crisis phenomena to more precise estimation of possible damage

and $\quad$ Real-time gathering of environmental and financial data
Preparation period

- Automatization of driving by autonomous cars (though it remains to be seen, if

- Development of smart safety equipment, technology, hardware and software hardware and software

Reaction period

- Smart technology as autonomous or distance-controlled information sources,

- Distance-controlled roadblocks

- Integration of tools for information exchange in various formats

- Enhancing the informational flow between passengers, environment and control centres

- Smart applications, helping with detection and localization of traffic crisis phenomena (e-call)

- Faster choosing of optimal evacuation routes

- Lowering pollution

- Smart technology as autonomous or distance-controlled information sources

- Real-time gathering of environment data

- Simplification of information transfer and general organizational management of actions

- Support of decision making systems

- Salvage operations coordination

- Acceleration of fundraising of money for reconstruction

- Reduction of duplicate calls amount

- Increase in volunteering awareness

- Enhancement of the readiness of citizens for sharing needed equipment

- Increase of the collaboration effectivity

- Development of smart safety equipment, technology, hardware and software

- Provision of additional information sources

- Simplification of spreading the calls for needed help

- Simplification and shortening of evacuation processes

- Providing more suitable and effective help in cooperation with professional units in solving crisis phenomena

- Development, production and implementation of smart safety equipment, technology, hardware and software

- Increase of protection for minimalization of losses decreasing production costs

- Interconnection with central control office with video, audio and possibly other perception means

- Speeding up the process of data processing

- Providing more suitable and effective help in cooperation with professional units in solving shared crisis phenomena

- Tools for help in crisis situations embedded in infrastructure

- Decrease of production costs

- Arrangement of building and other environment entities in a way, that ensures simple access of rescue units to all directions

- Tools for help in crisis situations embedded in infrastructure

- Real-time gathering of environmental and financial data sources 
additional financial and informational sources are available thanks to the use of smart components, that will be relevant in this phase of disaster management cycle?

In the following Table 1, the possibilities of smart components of individual systems to enhance safety in disaster management cycle are summarized. As it is a broad task to address, we compressed the information into tables, where identified possibilities are divided, based on periods of disaster management cycle, rather than its phases. This topic will be covered more closely in a separate article.

\section{Conclusion}

For further development of Smart Cities in the Slovak Republic, definitions for the smart and safe layers of every system of the concept were presented. By this summarization, we want to set up a base ground for understanding tools, actions and aims of systems, that belong to both Smart and Safe concepts. For the development of crisis management and resilience in Slovak cities, solutions, that will merge the philosophies of Smart and Safe City concepts need to be implemented and for successful implementation the relationships within a clear structure of concepts, systems, their layers and components need to be understood.

Resilience of the city is strongly affected by the smartness and safety of city systems. To create high resilience within the city, every system needs to work with high efficiency and in connection with other systems. As well as the relationships within the city are connected thorough systems, these connections need to be taken into account when building resilience in a smart way. That is why the paper presents not only, that safety is an essential quality within Smart City concept, but we also summarize possibilities of how smartness can be valuable asset within the concept of a Safe City. This topic is planned to be covered with more detail in future article, as it is a broad task to address. Another research focus is a methodological procedure of Smart City implementation, that should prosper from schematic clarification of Smart City and Safe City concepts in this paper. The aim is to help with assessment of safety within the city and to continually guide the executives into choosing the right solutions to implement, in order to get the most suitable solutions into the city.

In addition, we need to highlight, that in all the fields, the implementation of technology must be followed by the education of citizens in its use. Even the most advanced Smart City failed to fulfil its purpose, if the feature of Smart Citizen and Smart Education will be missing. And that might become a task, more challenging, than one might anticipate.
Acknowledgments With the support of the project VEGA 1/0628/18 Minimizing the level of experts' estimations subjectivity in safety practice using quantitative and qualitative methods.

This work was supported by the research project VI20152019049 "RESILIENCE 2015: Dynamic Resilience Evaluation of Interrelated Critical Infrastructure Subsystems", supported by the Ministry of the Interior of the Czech Republic in the years 2015-2019.

This work was jointly supported by the Slovak Research and Development Agency under the contract No. SK-CN-2017-0023.

This work was supported by the Internal Grant Scheme of Faculty of Security Engineering, University of Žilina from the grant No. IGP201805.

The views expressed, however, are solely those of the authors and not necessarily those of the institutions with which they are affiliated or of their funding sources. The authors are solely responsible for any errors or omissions.

Open Access This article is licensed under a Creative Commons Attribution 4.0 International License, which permits use, sharing, adaptation, distribution and reproduction in any medium or format, as long as you give appropriate credit to the original author(s) and the source, provide a link to the Creative Commons licence, and indicate if changes were made. The images or other third party material in this article are included in the article's Creative Commons licence, unless indicated otherwise in a credit line to the material. If material is not included in the article's Creative Commons licence and your intended use is not permitted by statutory regulation or exceeds the permitted use, you will need to obtain permission directly from the copyright holder. To view a copy of this licence, visit http://creativecommons.org/licenses/by/4.0/.

\section{References}

1. Blomqvist T (2018) Smart Tampere. Studio Libeskind, Tampere

2. Smart Tampere Ecosystem. http://smarttampere.fi/en. Accessed 7 Mar 2018

3. Helsinki Smart Region. https://www.helsinkismart.fi/. Accessed 15 Mar 2018

4. Lacinák M, Ristvej J (2017) Smart City, safety and security. Procedia Eng 192:522-527 ISSN: 1877-7058

5. Axis Communications (2015) A smart city is a city, where people feel safe. Brochure Axis Communications

6. Huawei Technologies Co., Ltd (2013) Huawei Smart City Solution. Brochure Huawei Technologies

7. Fedorov V, Robnik A, Terekhov A (2012) "Safe City"-an open and reliable solution for a safe and Smart City. https:// $\mathrm{pdfs}$ s e man ti c s c hol a r o r g/fff $6 /$ d861abe7dc3d022c5e7b1d4f25d87d2850e8pdf. Accesseed 15 Mar 2018

8. Finka M, Ondrejička V, Jamečný L' (2016) Urban safety as spatial quality in smart cities. Bratislava. https://doi.org/10.1007/978-3319-33681-7 73

9. Giffinger R, Fertner Ch, Kramar H, Pichler-Milanovic N, Meijers E Europeansmartcities 3.0 (2014) Ranking http://www.smart-cities. $\mathrm{eu} /$ ?cid $=3 \&$ ver $=3$. Accessed 12 May 2018

10. The Worldwatch Institute Island Press (2016) Can a city be sustainable? (State of the world) Washington DC

11. Benevolo C, Dameri RP, D'Auria B (2015) Smart Mobility in Smart City. In Torre Tet al (ed) Empowering organizations lecture notes in information systems and organisation, vol 11. Springer, Heidelberg, pp 13-28

12. Çiğdem Ç (2016) The key role of the smart traffic applications in Smart City systems international conference on advances in science ICAS Istanbul. https://doi.org/10.13140/RG.2.2.24617.39527 
13. Docherty I, Marsden G, Anable J (2018) The governance of smart mobility. Transportation Research Part A: Policy and Practice 115: 114-125. https://doi.org/10.1016/j.tra.2017.09.012

14. Mrityunjaya DH, Naveen K, Laxmikant Sameer A, Kelagadi HM (2017) Smart transportation. International Conference ON I-SMAC (IOT in Social, Mobile, Analytics and Cloud) (I-SMAC), IEEE. https://doi.org/10.1109/I-SMAC.2017.8058235

15. Zhili L, Xudong J, Wen Ch (2012) Solving the last mile problem: ensure the success of public bicycle system in Beijing. Procedia social and behavioral sciences 43:73-78

16. Hadden D What is the Smart in Smart Government http:// freebalance.com/open-government/what-is-the-smart-in-smartgovernment/. Accessed 25 Oct 2018

17. Lunde K Nordic Smart Government https:// nordicsmartgovernment.org/. Accessed 25 Oct 2018

18. Mutiara D, Yuniarti S, Pratama B (2018) Smart governance for smart city. IOP Conference Series: Earth and Environmental Science 126. https://doi.org/10.1088/1755-1315/126/1/012073

19. Smart Tampere: Smart Government \& Citizen. http://smarttampere. fi/en/smart-ecosystem-themes/smart-government-and-citizen. Accessed 25 Oct 2018

20. NEC: Smart Government https://www.nec-enterprise.com/ solutions/Smart-Government-229. Accessed 25 Oct 2018

21. Rochet C (2015) Urban lifecycle management: a research program for smart government of smart cities. Institut de management Public et Gouvernance Territoriale, Marseille, pp 33

22. ByeongGuk K (2015) Daily edventures http://dailyedventures.com/ index.php/2013/03/11/korea/. Accessed 23 Apr 2018

23. Capdevila I, Zarlenga MI Smart City or smart citizens? The Barcelona case. Journal of Strategy and Management 8(3):266-282

24. Cardullo P, Kitchin R (2017) Being a 'citizen' in the smart city: up and down the scaffold of smart citizen participation. The Programmable City Working Paper 30, Maynooth, p 24

25. Bull R (2016) Smart citizens for smart cities: Participating in the future. Proceedings of The Institution of Civil Engineers - Energy 169(3):93-101

26. Zhi-Ting Z, Ming-Hua Y, Riezebos P A Research framework of smart education, Smart Learning Environments. https://slejournal. springeropen.com/articles/10.1186/s40561-016-0026-2. Accessed 26 Oct 2018

27. Kresin F (2016) Smart cities value their smart citizens in the book: urban Europe. Fifty Tales of the City chapter: 22 Publisher: Amsterdam University press editors: Mamadouh V. \& Wageningen a pp. 6 DOI: https://doi.org/10.26530/OAPEN_ 623610

28. Smart Tampere: Smart Industry. http://smarttampere.fi/en/smartecosystem-themes/smart-industry. Accessed 26 Oct 2018
29. Investopedia Sharing Economy. https://www.investopedia.com/ terms/s/sharing-economy.asp\#ixzz5IJNu1iSI. Accessed 26 Oct 2018

30. Kumar TMV, Dahiya B (2017) Smart economy in smart cities, in book: smart cities, local community and socio-economic development: the case of Bologna, 1st edition, Chapter 1, pp 3-76

31. Christiansen $\mathrm{H}$ Ch, Kongsmark E Defining a Smart Energy City http://urbantransform.eu/about/smart-energy-city/. Accessed 26 Oct 2018

32. Tokody D, Schuster G, Papp J (2015) Smart City, smart infrastructure, smart railway. Zrenjanin, Serbia

33. Meier M Smart Energy What is the Risk?, http://www. remotemagazine.com/main/articles/smart-energy-what-is-therisk/. Accessed 26 Oct 2018

34. Lund H, Østergaard P A, Connolly D, Mathiesen B V Smart energy and smart energy systems. https://doi.org/10.1016/j.energy.2017. 05.123. Accessed 26 Oct 2018

35. Cormia R D Getting Smart About Smart Energy. https://www. slideshare.net/rdcormia/getting-smart-about-smart-energy. Accessed 26 Oct 2018

36. IGI Global What is Smart Environment. https://www.igi-global. com/dictionary/smart-environment/27178. Accessed 26 Oct 2018

37. SlideShare Smart environment. https://www.slideshare.net/ franson0605/smart-environment. Accessed 26 Oct 2018

38. Tóth A (2017) Green infrastructure - its elements, areas and systems. National Journal/Magazine 22(3):8-9

39. Mikulecký P (2012) Smart environments for smart learning. DIVAI 2012 - 9th International Scientific Conference on Distance Learning in Applied Informatics, Štúrovo

40. Lovecek T et al (2016) Level of protection of critical infrastructure in the Slovak Republic. In: Conference: international conference on engineering science and production management (ESPM), pp 163 168.

41. Nosek R et al (2017) Analysis of paper sludge pellets for energy utilization. Bioresources 12(4):7032-7040

42. Holubčík M et al (2012) Optimization of the production process of wood pellets by adding additives. International Journal of Energy Optimization and Engineering 1(2):20-40

43. Holubčík M et al (2015) Factors affecting emission concentrations in small heat sources. Komunikácie: Communications - Scientific Letters of the University of Zilina 17(3):18-24

44. Menon NVC, Sahay R (2015) Role of Geoinformatics for disaster risk management. In: Ristvej J, Zagorecki A, Riska T (eds) Crisis management II. - part 2. Application software in crisis management. EDIS - editorial Centre of the University of Žilina, Žilina

Publisher's note Springer Nature remains neutral with regard to jurisdictional claims in published maps and institutional affiliations. 